\title{
DE82 013197
}

\section{CASCADES FOR HYDROGEN ISOTOFE SEPARAIIO.I USING NETAL HYDRIDES*}

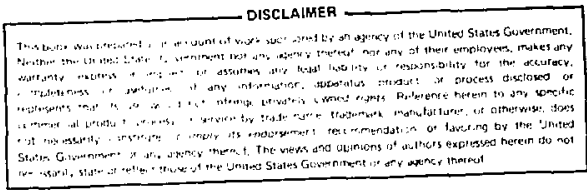

F. B. Hill and V. Griezlict*

Brookhaven National Laboratory

Upton, New York 11973, U.S.A.

\section{ABSTRACT}

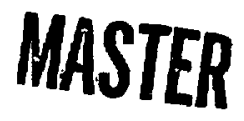

Designs are presented for continuous countercurrent hydrogen isotope separation cascades based on the use of metal hydrides. The cascades are made up of pressure swing adsorption (PSA) or temperature swing adsorption (TSA) stages. The designs were evolved from consideration of previously conducted studies of the separation performance of four types of PSA and TSA processes.

\section{INTRODUCTION}

One of the important applications envisioned for metal hydrides is the separation of hydrogen 1sotopes. The separations permitted by 1sotope effects in metal-hydrogen systems are particularly appropriate for applications with a gaseous hydrogen feed, such as in the recovery of deutertum from 1ndustrial hydrogen streams or the processing of the fuel of fuston reactors.

The present work deals with the design of cascades for hydrogen 1sotope separation when using metal hydrides in pressure swing adsorption (PSA) or temperature swing adsorption (TSA) stages. The results of previous studies $[1,2,3\}$ on the separation performance of Individual stages of these processes are used to develop design principles for such cascades. Illustrative designs are presented for a tritiun removal problem.

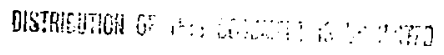

* This work was supported by the Chemical Sclences Division, U.S. more Depertment of Enerzy under Contract No. DE-ACO2-76CHOnO16.

**1siting Chemlcal Englneer. Permanent address: UnIversity of Zagreb, Zagreb, Yugoslavia. 
PROPERTIES OF PSA AND TSA STAGES

In the earlier studies (Op. cit.) on Individual PSA and TSA stages a stream of iritiated hydrogen was used as the feed and vanadium was used statis

as the solid phase. In the vanadlum-hydrogen system at the temperatures used in these studies an equilibriun 1sotope effect exists such that tritiun is preferentially takel up by the solfd from a protiun-tritium mixture $[4,5]$. A kinetic 1sotope effect also exists and was evident in the earlier work. In the kinetic 1sotope effect, tritium is raken up and released more slowly than protium during an absorption-desorption cycle. The two effects are opposite in their separation hehavior.

The PSA and ISA processes studied are cycllc gas-sol1d separation processes which are widely used for Industrial gas separations. PSA In particular is routinely used for the purffication of hydrogen.

The version of PSA principally used in the earlier work was a twocolum version known as heatless adsorption. Detalls of the heatless adsorption eycle are glven in Reference I. When this process was operated with short cycles $(2 \mathrm{~min}$. Wh $45.7 \mathrm{~cm}$ long $x 0.77 \mathrm{~cm} 1 . d$. colums contalning $60 \mathrm{~g} \mathrm{~V}, 200-300$ std $\mathrm{cm}^{3} / \mathrm{min}$. high pressure feed flow rate), the kinetic 1sotope effect controlled separation and the process produced a high pregsure product enrfched in tritiun and a low pressure product depleted 1n tritium. Rapld cycling was achleved by selecting the temperature ( $373 \mathrm{k})$ and high (1030 kPa) and $10 \mathrm{w}(103 \mathrm{kPa})$ pressures so that cycling occurred wholly within the monohydrlde phase. Iong cycles (up to $4 \mathrm{hr}$ with the same column and flow rate range as above) led to separations controlied by the equilibrlum Isotope effect. Long cycles were made not only possible but necessary by lowering the temperature to 298R when using the same low and high pressures. Then cycling occurred between the monohydride and dihydride phases and the process produced a 
high pressure product depleted in tritium and a low pressure product enriched in tritiun. Thus two versions of the PSA process used in the reference studfes were two-column PSA operated in the single phase mode and in the two phase mode [1]. A third version involved a single column process operating in the single phase mode [3]. The single column process is Identical to the two column process when the latter was operated with no purge. A fourth cyclic process version fnvolved two columns but temperature was cycled rather than pressure [2]. This TSA process was operated in the single phase mode. Even though this process was operated wholly within the monohydride phase, because the column temperature could not be changed rapldly, the cycles were long (30 m1n) and the ISA process was controlled by the equilibrium 1sotope effect.

For each of the process versions studled the stage separation factor, $\alpha$, was measured as a function of the product cut, $\theta$. The stage separation factor is the average steady state mole fraction of tritium in the enriched product stream divfded by the average steady state tritfum mole fraction in the depleted product stream. The product cur is the moles of enriched product per cycle divided by the total moles of feed Introduced per cycle. These measurements for the four process versions are sumarlzed in Fig. I.

\section{CASCADES OF PSA AND TSA STAGES}

Multiplication of the separation effect of a single stage is accomplished by the use of a serles of stages arranged to form a continuous countercurrent cascade as shown in Fig. 2. Each of the rectangles in this flgure represents a PSA or TSA stage, and the arrows between stages represent the flow of enrfched and depleted streams from stage to stage. The enrfched stream from a stage flows upward and the depleted stream dowaward. 
The feed to a given stage is the sum of the depleted stream from the stage above and the enriched stream from the stage below. Although these streams are shown entering a glven stage separately, in practice they enter together as shown in FIg. 3. This figure shows the principal 1tens of equipment for each stage. Valves and instrumentation are not shown. Since one of the streams making up the feed will be at low pressure and the feed to the stage must be at the high pressure, a compressor is required for each stage. Also sfnce all flows are latermittent, a surge vessel is required. It is assumed the high pressure and low pressure are constant throughout the cascade. This is a reasonable approximation if the pressure drop through the columns during flow at high pressure is small. This was the case experimentally.

Design of a cascade of the kind shown in Fig. 2 consists for present purposes of determining the number of stages required to accomplish a specified separation and determining certain indices of the size of the cascade and of the power required by the compressors. The design proceeded in the custonary way [ $[$ ] by developing overall waterial balances and partial (tritium) material balances around the entire cascau's and around the stripplng and enrichlng sections. Detalls are onftted because of space Ifoltations. First order difference equations resulted which could be summed after making two assumptions. These were that the cut and the stage separation factor were constant throughout each section of the cascade although values in the strippling section were different from those in the enfiching section. Tapered cascades resulted from the assumption of constant cuts in the two sections. The assumption of stage separation factors independent of tritium mole fraction restricted the design to situations in wich the FT mole fraction is swall so that the 
$T_{2}$ mole fraction is negligible. Thus the design method is restricted to a two-component systen. To avold encountering pinches during the sumation, restrfetions on the ranges of values of cuts in the two sections were necessary. The result was that cuts greater than 0.5 were desirable In the stripplng section and cuts less than 0.5 were desirable in the enriching section. One sees from Fig. I that equilibrim stages (two colum two phase mode PSA and two-colum single phase mode ISA) are therefore approprlate for use in the stripping section, and kinetic stages (one- and two-colum single pinase mode PSA) are sultable for the enriching section.

Summation of the difference equations for the two sections leads to determination of the numbers of stages required in each section and of the Interstage flow rates for each stage.

Indices of the s1ze and power requirements for the cascade are obtalned by summing up the high and low pressure flow rates for the entire cascade. The total low pressure flow rate is that which must be compressed from the low pressure to the high pressure and is proportional to the total power requirement for the cascade. The total high pressure feed flow rate is the sum of the total high pressure flows leaving each stage plus the sum of the low pressure flows after compresston. The total high pressure feed flow rate is an index of the size (volume) of the cascade.

\section{ILIOSTRATIVE CASCADE DESIGNS}

The method outlined above was used to prepare 1llustratfve designs for a specific hydrogen isotope separation problem. The problem involved removal of trfelum from hydrogen and had earlier been used by Benenat1 [7] so lliustrate the use of a cassade of dual temperature exchange stages using vanadium hydride for hydrogen 1sotope separation. 
The problem is stated as follows. The hydrogen in $300 \mathrm{~kg} \mathrm{H} 20 /$ day contalning $\mathrm{I} \mathrm{Cl} \mathrm{T} / \mathrm{kg}$ is to be decontaminated yielding a depleted product contalning one percent of the tritium fed and an enriched product reduced In volume by a factor of 30 . The present interest is restricted to the hydrogen 1sotope separaition 1tself and the conversions of water to hydrogen and vice versa are 1gnored. For the gaseous separation problem the feed and product flow rates and the corresponding compositions (RT mole fractions) are

$$
\begin{array}{lll}
F=1.927 \times 10^{-4} \mathrm{Kg}-\text { mole } \mathrm{H}_{2} / \mathrm{s} & z_{F}=3.1 \times 10^{-7} \\
P=6.42 \times 10^{-6} \mathrm{Kg} \text {-mole } \mathrm{B}_{2} / \mathrm{s} & y_{P}=9.21 \times 10^{-6} \\
\mathrm{~W}=1.863 \times 10^{-4} \mathrm{Kg} \text {-mole } \mathrm{H}_{2} / \mathrm{s} & x_{\mathrm{W}}=3.21 \times 10^{-9}
\end{array}
$$

The separation factor-cut relation for the single phase mode processes shown In FIg. 1 was used for the enrlching section and the relation in this figure for the two-column two-phase mode PSA process was used for the stripping section. Interest was restricted to this PSA process in the stripping section since it had larger stage separation factors than the TSA process, the only other equilibrium process.

In carrying out the design procedure the number of stages in the stripping section was calculated as a function of $\theta_{S}$ for $0.55 \leq \theta_{S} \leq$ 0.95. Then for each value of $\theta_{S}$ the nuber of stages in the enrlching section was calculated as a function of $\theta_{E}$ where $0.05 \leq \theta_{E} \leq 0.45$. Extrapolated values of the $\alpha-\theta$ relatione were used when required. During the course of these calculations the total low pressure flow rate and total feed flow rate were also calculated. The results are shown in Table 1.

Solutions were not obtalned for all $\theta_{\mathrm{S}} \theta_{\mathrm{E}} \operatorname{combinations.~Por~}$ those comblnations for which there are no entries in Table 1 convergence of an tterative procedure used for calculation of the enriching section 
was not obtalned in 50 1terations. Presumably not all combinations are possible, probably because of the pinch phenomena mentioned earlier. The matter was not examined further. Convergent solutions were found for all values of $\theta_{S}$ for large values of $\theta_{E}$. Convergence was not obtalned when $\theta_{\mathrm{E}}$ was small.

The number of stages in the stripping section ranges from 3 to 15 and depends only on $\theta_{S}$. It becomes small as $\theta_{S}$ and hence $\alpha_{S}$, becomes large. The number of enrlching stages ranges from 11 to 14 and is relatively insensitive to efther variable. The total low pressure flow rate and the total high pressure feed flow rate vary with both $\theta_{S}$ and $\theta_{E}$. They become small as both $\theta_{S}$ and $\theta_{E}$ become small. Thus cascades of small stze with small power requirements have many stages and vice versa. An economic optimum may be expected to involve a compromise between number of stages on the one hand and cascade volume and power requirement on the other. The location of this optimum may depend strongly on cost of the hydriding metal or alloy used.

The designs in Table 1 are not optimal for various reasons. Principal among these 1 s the fact that different $a-\theta$ relations may be possible and require further experimental exploration. For instance smailer cuts may be possible in the strlpping section whlle malntalning high separation factors. Simllarly the possibllity of obtalning reasonably high separation factors at larger cuts in the enriching section requires exploration. Also, the pressure range used in the experiments on which the present designs vere based is large and would result in large power requirements for the cascade. A smaller pressure range may produce separation factors which are not much reduced from present values and at the sarue time would reduce power and compressor size requirements. 
Becauge the present designs are not optimal a detalled comparison of them with the design of Benenat1 [7] would not be significant. It is worthwhlle mentloning however that the number of stages in the present desfgn ranges from 14 to 26 whereas the dual temperature exchange deslgn required 48 stages. Further, the PSA stages are actual stages whereas for the dual temperature exchange process they are ideal stages.

\section{REFERENCES}

1. Wong, Y. H., F. B. A111, and Y. N. I. Chan, Separation Sci. Tech. 15 (1980) 423.

2. HIII, F. B., Y. W. Wong, and Y. N. I. Chan, A.I.Ch.E. Journal 28, (1982) 1.

3. Wong, Y. W. and F. B. Hill, Chem. Eng. Coumun., in press.

4. Wiswal1, R. R, and J. J. Re111y, Inorg. Chem. 11 (1972) 1691.

5. Wong, Y. W., and F. B. Hill, A.I.Ch.E. Journal 25 (1979) 592.

6. Pratt, H. R. C., "Countercurrent Separation Processes," Elsevier, Ams terdam (1967).

7. Benenat1, R. F., BNL 21294 (1976). 
Table 1.

Cascade Parameters for Tritiun Removal Problen

Entrles for each $\theta_{S}{ }^{-\theta_{E}}$ combination $\quad\left\{\begin{array}{l}n_{S} / n_{T} \\ \eta_{L} / Q / F\end{array}\right.$

$\begin{array}{llllll}\theta_{\mathrm{S}} / \alpha_{\mathrm{S}} & 0.55 / 1.42 & 0.65 / 1.90 & 0.75 / 2.38 & 0.85 / 2.86 & 0.95 / 3.34\end{array}$

$\theta_{\mathrm{E}} / \alpha_{\mathrm{E}}$

$0.25 / 1.46$

$0.35 / 1.44$

$15 / 26$

$5 / 17$

$1 / 15$

$3 / 16$

$0.136 / 0.236$

$0.247 / 0.359$

$0.787 / 1.108$

$4.34 / 5.99$

$0.45 / 1.40$

$15 / 26$

$7 / 19$

$5 / 17$

$4 / 16$

$3 / 17$

$0.191 / 0.345$

$0.216 / 0.371$

$0.439 / 0.744$

$1.45 / 2.43$

$8.39 / 14.09$

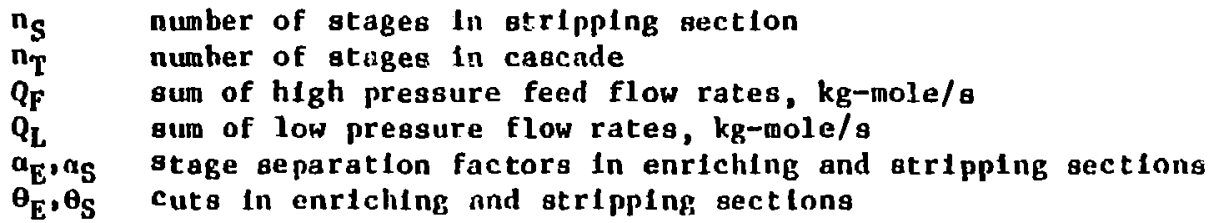




\section{FIGURE CAPIIONS}

F1g. I Stage sparation factors for PSA and ISA processes. Twocolumi PSA [I]: $P_{H}=1030 \mathrm{kPa}, P_{L}=103 \mathrm{kPa}$. Single phase, $T=373 \mathrm{~K}$. Two phase, $T=298 \mathrm{~K}$. TSA [2] : $\mathrm{P}_{\mathrm{H}}=689 \mathrm{kPa}, \mathrm{T}_{\mathrm{L}}=333 \mathrm{~K}, \mathrm{P}_{\mathrm{L}}=620 \mathrm{kPa}, \mathrm{T}_{\mathrm{H}}=423 \mathrm{k}$. Single colum PSA [3]: $T=372 \mathrm{~K}, \mathrm{P}_{\mathrm{B}}=1030 \mathrm{kPa}, \mathrm{P}_{\mathrm{L}}=$ $103 \mathrm{kPa}$.

F1g. 2 Schematlc diagram of continous countercurrent cascade.

F1g. 3 Schematic diagram of princlpal itens of equipment assoclated with a single PSA or TSA stage. 


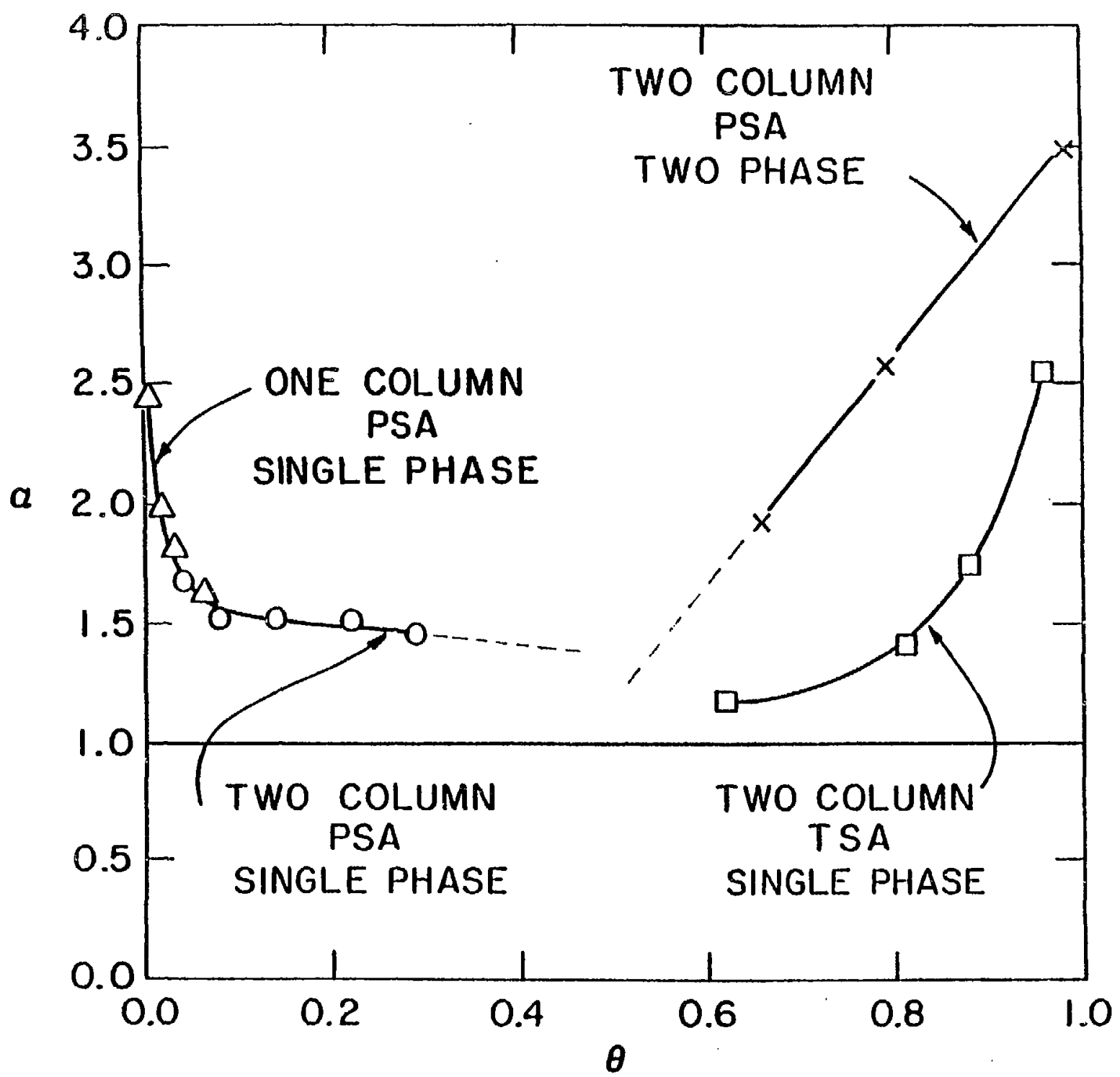




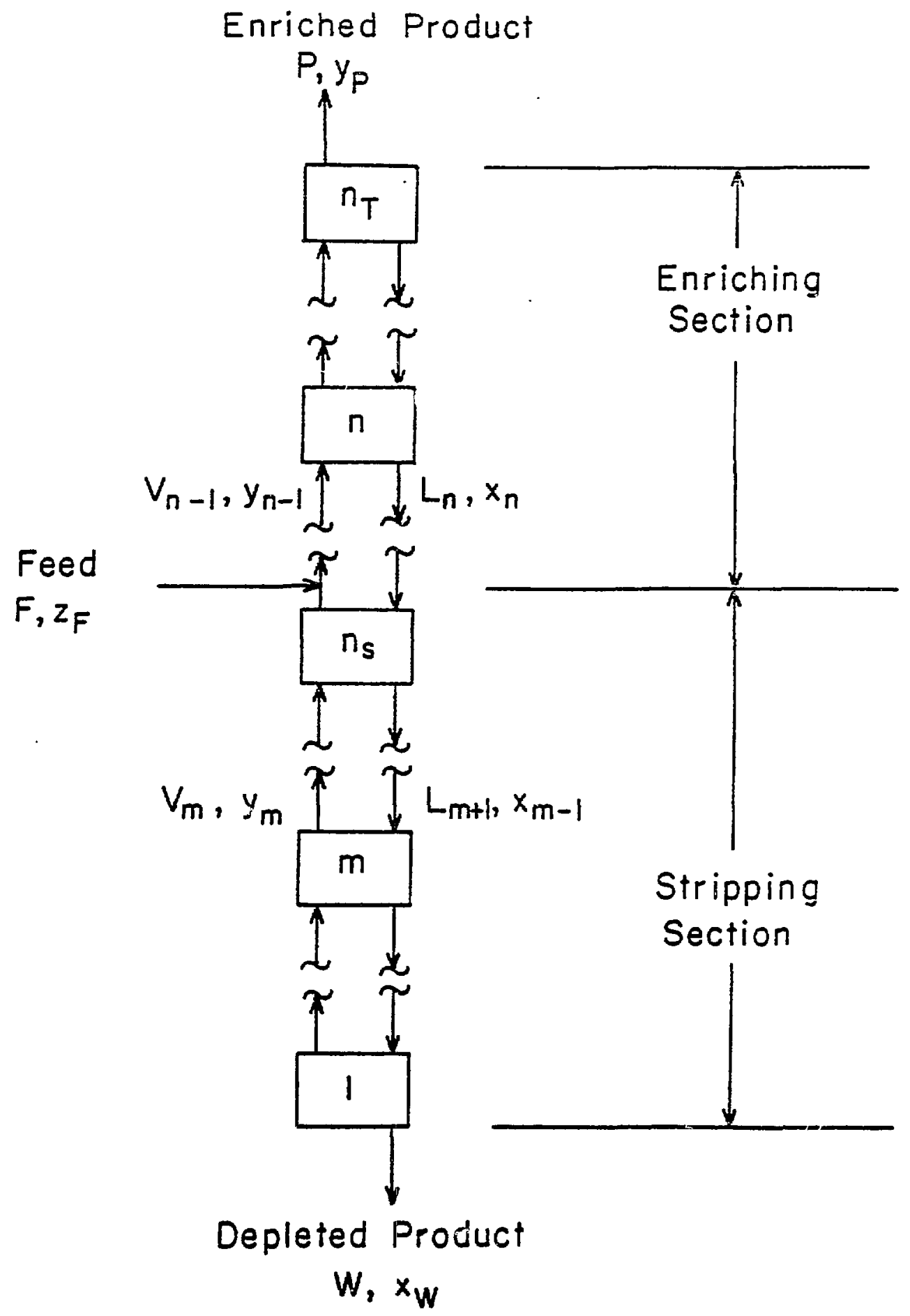

F1gure 2 


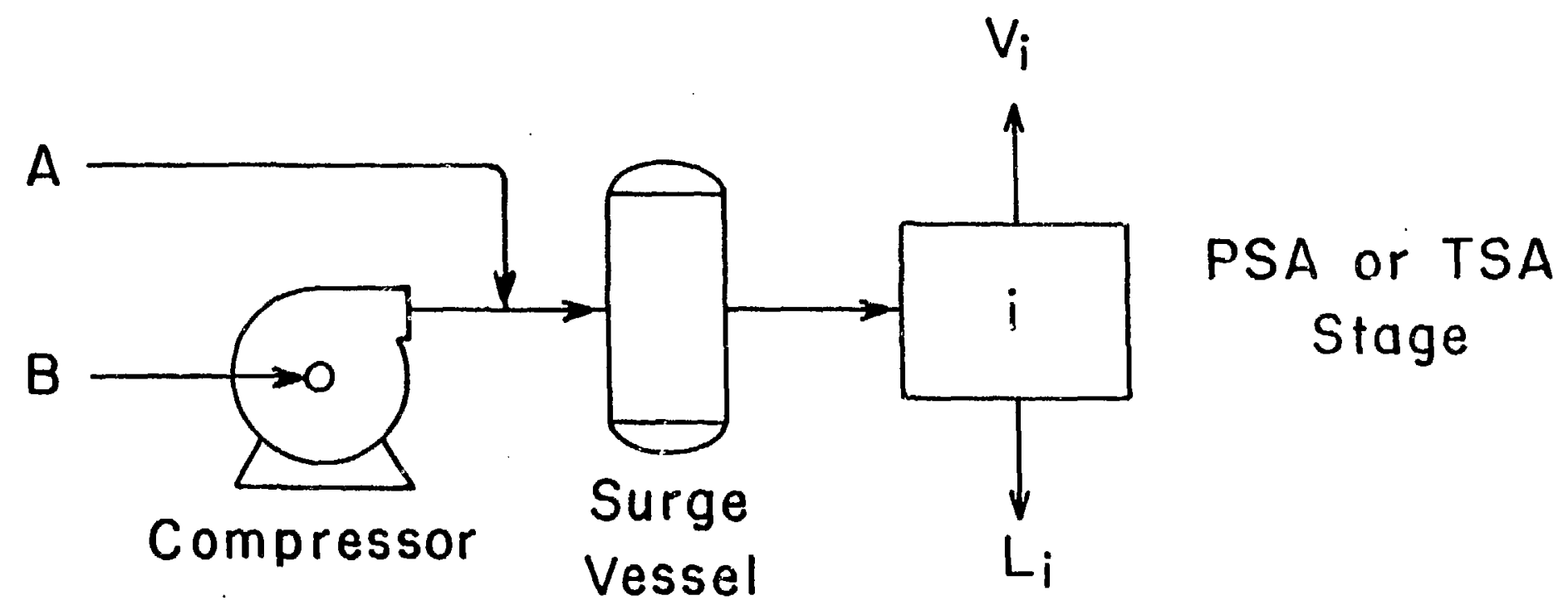

\begin{tabular}{|c|c|c|}
\hline Lecation & $A$ & $B$ \\
\hline Stripping & $L_{i+1}$ & $V_{i-1}$ \\
\hline Enriching & $V_{i-1}$ & $L_{i+1}$ \\
\hline
\end{tabular}

